\title{
LXXV. Observations on the green teas of commerce
}

\section{Robert Warington Esq.}

To cite this article: Robert Warington Esq. (1844) LXXV. Observations on the green teas of commerce, Philosophical Magazine Series 3, 24:162, 507-514, DOI: 10.1080/14786444408644914

To link to this article: http://dx.doi.org/10.1080/14786444408644914

册 Published online: 30 Apr 2009.

Submit your article to this journal

Џ Article views: 2

Q View related articles $\asymp$ 
spirits of wine, or japanners' gold size, are then to be placed round the margin, so as completely to inclose the oil, and the crystals are permanently preserved for observation. It may be perhaps as well to observe, that the one layer of varnish must be allowed to dry for about twenty-four hours before the next is applied, and that during this time the slider must be maintained in a flat position.

LXXV. Observations on the Green Teas of Commerce. By Robert Waring'ton, Esq.*

I examining lately some samples of tea which had been 1 seized, from their being supposed to be spurious, my attention was arrested by the varied tints which the sample of green tea exhibited, extending from a dull olive to a bright greenish blue colour. On submitting this to the scrutinizing test of examination by the microscope with a magnifying power of one hundred times linear, the object being illuminated by reflected light, the cause of this variation of colour was immediately rendered apparent, for it was found that the curled leaves were entirely covered with a white powder having in places a slightly glistening aspect, and these were interspersed with small granules of a bright blue colour, and others of an orange tint: in the folded and consequently more protected parts of the curled leaves these were more distinctly visible. By shaking the whole of the sample mechanically for a short time a quantity of powder was detached, and from this a number of the blue particles were picked out under a magnifying glass, by means of the moistened point of a fine camel's hair pencil. On being crushed in water between two plates of glass they presented, when viewed by transmitted light, a bright blue streak. This change in the method of illuminating the object was necessary for the purpose of seeing the action of the following tests:- A minute drop of a solution of caustic potash was introduced by capillary attraction between the glass plates, and the blue tint was immediately converted to a dark bright brown, and the original blue colour again restored by the introduction of a little dilute sulphuric acid. It was therefore evident that these particles consisted of the ferrocyanide of iron or Prussian blue. The orange granules on examination proved to be some vegetable colouring substance.

To ascertain if possible the nature of the white powder observed on this sample, I separated some of the dust, and heated it to redness with free exposure to the air; the whole of the vegetable matter and Prussian blue was thus destroyed,

* Communicated by the Chemical Society; having been read February 5,1844 . 
and a white powder, with a slight shade of brown, was obtained. This dissolved by boiling in dilute hydrochloric acid, and when tested with solution of chloride of barium gave indications of sulphuric acid; it was then evaporated to dryness and again acted upon by very dilute hydrochloric acid; a trace of silica remained undissolved. Solution of ammonia being added threw down a little alumina and oxide of iron, and the ammoniacal solution treated with oxalic acid gave a precipitate of oxalate of lime. A second portion of the powder after calcination was boiled for some time in distilled water, and yielded a solution containing sulphate of lime; this latter substance, therefore, and some other body containing silica, alumina, and perhaps lime, formed the white powder observed. This substance I believe to be kaolin, or powdered agalmatolite, the figure stone of the Chinese. I venture this conjecture not only from the ingredients found, but also from the gloss which the rubbed parts of the curled leaves always assume, and which these materials would be well fitted to produce.

Four or five other samples of green teas were then subnitted to the same method of examination, and only one of them proved to be free from these blue granules; this sample was a high-priced tea, and had been purchased about two years; it appeared covered with a very pale blue powder, instead of the white with the blue particles interspersed, as exhibited by the others.

Being still in doubt as to whether this powder and colouring was an adulteration practised in this country or not, $I$ applied to a most extensive wholesale dealer of the highest respectability, and from him obtained a series of samples, each being an average from a number of original chests, and from these I gathered the following results by examination, as before, with the microscope. No. 1. Imperial. The leaf, where seen beneath the superficial coating, was of a bright olive brown colour, with small filaments on its surface; it was covered with a fine white powder and with here and there a minute bright blue particle, at times having the appearance of a stain. No. 2. Gunpowder. Similar to No. 1, but the filaments not visible: this may have arisen from the tight and close manner in which the leaf was curled. No. 3. Hyson. The same as No. 1, the blue particles being perhaps more frequent. No. 4. Young Hyson. The same. No. 5. Twankey. The leaf of this had more of a yellow hue, and was profusely covered with white powder, having the blue particles also more thickly strewn over the surface. It was evident from the examination of these teas that they arrive in this country in an adulterated or factitious state. 
On detailing what I had thus found to the friend who had favoured me with the preceding samples, he inquired if I had examined any unglazed teas. This appellation immediately arrested my attention, and I requested to inspect some of them, and found that they possessed externally a totally different aspect, indeed, as far as their colour was concerned, not to be like green teas. They were of a yellow-brown tint without a shade of green or blue, but rather tending on the rubbed parts to a blackish hue. I afterwards received two samples of unglazed teas, specified as of very fine quality, accompanied by two others of the ordinary or, as they are called, in contradistinction, glazed varieties, also of a very superior quality. These were therefore immediately submitted to examination. No. 6. Unglazed Gunpowder. It presented the same colour under the microscope as when viewed by the unassisted eye, was filamentous and covered with a white powder inclining to a brown tint, but no shade of blue was visbile. No. 7. Unglazed Hyson. The same as No. 6. No. 8. Gunpowder glazed. Filamentous, covered with a powder of a very pale blue, and the blue granules being but rarely seen. No. 9 . Hyson. The same as No. 8. No. 10. Pidding's Howqua, purchased at Littlejohn's at $8 s .6 d$. per catty package. This was evidently of the glazed variety; it was filamentous and covered with a pale blue powder interspersed with bright blue granules. No. 11, entitled Canton Gunpowder. This was a splendid sample of the glazed variety, as far as colour was concerned; it was more thickly powdered and blued than any that $I$ have examined, and the dust rose from it in quantity when poured from one paper to another. A great many other samples of ordinary green teas were examined, with much the same results; the cheaper teas, or those in general use, and which form the bulk of the imports, being similar to Nos. 5 and 11, and being represented by Twankeys and lowpriced Hysons or Gunpowders.

After several unsuccessful experiments, I found that with a little care the whole of this powder or facing, if I may be allowed the term, it being entirely superficial, could be easily removed from the tea, by simply agitating the sample briskly for a few seconds in a phial with distilled water, and then throwing the whole on a lawn or muslin filter, in order to strain the liquid, with the suspended matter, from the leaves as rapidly as possible. After this operation the tea presented a totally altered aspect, as may be supposed; in fact, changing its colour from a bluish green to a bright and lively yellow or brownish yellow tint, and I found that with care it could be redried at a temperature below $212^{\circ}$ without even uncurl- 


\section{$510 \mathrm{Mr}$. Warington on the Green Teas of Commerce.}

ing the leaf, and without apparent loss of any of its characteristic qualities. When the drying was complete the sample appeared nearly as dark as the ordinary black teas, and when examined by the microscope presented a smooth surface, per fectly free from the previously observed facing, and having all the characters of black tea, with the exception of the corrugated aspect which is common to the greater part of the teas of the latter variety, and which evidently arises from their having been exposed in the operation of drying to a much higher temperature. The greenish-coloured turbid liquid which passed through the meshes of the muslin filter was allowed to deposit the matter suspended in it, which was then washed and collected. These sediments, obtained from various samples, were submitted to the following course of chemical examination. They were, in the first instance, tested with a solution of chlorine gas in water, to ascertain if the colouring material was indigo or other vegetable colour; this substance, as we shall presently see, having been supposed by some persons to be the one employed by the Chinese for the purpose of imparting the blue tint to some of their green teas. In no case, however, that I have yet examined have I found this to be the case; but the colouring agent has invariably proved to be the ferrocyanide of iron or Prussian blue. 'The presence of this compound was next evidenced by adding a small drop of caustic potash to a little of the sediment under examination, when the green hue was instantly converted to a bright reddish brown, the original blue appearance being again restored by the subsequent addition of a little diluted sulphuric acid. The other ingredients of the faring were sought for in the manner stated in the previous part of this paper, and also by heating a part of the sediment, after calcination and free exposure to the air, with carbonate of sola, to fusion, which, in the case of sulphate of lime being present, formed sulphate of soda and carbonate of lime, and these were each subsequently tested for.

By these means Nos. 5, 8, 10 and 11 were found to be faced with Prussian blue and sulphate of lime. Nos. 6 and 7 gave no indication of Prussian blue, but of sulphate of lime only. The sulphate of lime from some samples appeared to be crystallized gypsum reduced to a fine powder, the coarser particles still exhibiting a crystalline structure.

Through the kindness of $\mathrm{Mr}$. Greene, of the East India House, I was enabled to obtain samples of the Assam teas in a genuine condition; No. 12. Imperial, No. 13. Gunpowder, and No. 14. Hyson. They had none of the blue granules, were very filamentous, and presented the same appearance as 
the unglazed varieties, but brighter in colour; the facing was apparently sulphate of lime. No. 15. Assam Hyson, of the last importation; it was of the unglazed variety, with the superficial white powder having a slight brown tint, and consisting of a minute quantity of sulphate of lime with a little alumina.

It appears, therefore, from these examinations that all the green teas that are imported into this country are faced or covered superficially with a powder consisting of either Prussian blue and sulphate of lime or gypsum, as in the majority of samples examined, with occasionally a yellow or orange-coloured vegetable substance; or of sulphate of lime previously stained with Prussian blue, as in Nos. 8 and 9, and one of those first investigated; or of Prussian blue, the orange-coloured substance with sulphate of lime and a material supposed to be kaolin, as in the original sample; or of sulphate of lime alone, as in the unglazed varieties. It is a curious question what the object for the employment of this facing can be; whether, as when sulphate of lime alone is used, it is simply added as an absorbent of thelast portions of moisture which cannot be entirely dissipated in the process of drying, or whether it is only, as I believe, to give that peculiar bloom and colour so characteristic of the varieties of green tea, and which is so generally looked for by the consumer, that the want of the green colour, as in the unglazed variety, I am informed affects the selling price most materially. This surely can only arise from the want of the above facts being generally known, as it would be ridiculous to imagine that a painted and adulterated article, for such it must really be considered, should maintain a preference over a more genuine one. In looking over the various authors who have written on the subject of tea, I have observed the following curious statements bearing on the above subject, and fully confirming many of my results, and with which I shall close the present communication.

In Dr. Horsfield's valuable translation * on the subject of the manufacture of tea in Java, we find, at page 36, the following dialogue :-

"Visitor. Is it indeed the case that tea is so much adulterated in China?

"Superintendent. Unquestionably! but not in the interior provinces, for there exist rigid laws against the adulteration of tea ; and all teas, as they come out of the plantations, are examined on the part of government, to determine whether they are genuine; but in Canton, which is the emporimm of teas, and especially at Honân, many sorts, indeed most teas,

* Essay on the Cultivation and Manufacture of Tea in Java, translated from the Dutch by Thomas Horsfield, M.D., F.R.S. 
are greatly adulterated, and that with ingredients injurious to health, especially if too much of these ingredients be added. This is especially the case with the green tea, in order to improve the colour; and in this manner to add to the value of tea in the eyes of the common consumers.

"Visitor. Are these ingredients known?

"Superintendent. Most of them are certainly known; they have been communicated to government (we presume the Dutch government), while at the same time the privilege has been requested that they might not be employed here; and although this occasions loss, the request has been granted, and it has been ordered by government that not the least admixture should take place, either to improve the colour or taste of the tea, even in such cases where this might be clesirable."

Dr. Royle states*, "The Chinese in the neighbourhood of Canton are able to prepare a tea which can be coloured and made up to imitate various qualities of green tea; and large quantities are thus yearly made up." And Dr. Dickson $\uparrow,-$ "The Chinese annually dry many millions of pounds of the leaves of different plants to mingle with the genuine, as those of the ash, plum, \&c., so that all spurious leaves found in parcels of bad tea must not be supposed to be introduced into them by dealers in this country. While the tea trade was entirely in the hands of the East India Company few of these adulterated teas were shipped for this country, as experienced and competent inspectors were kept at Canton, to prevent the exportation of such in the Company's ships; but since the trade has been opened all kinds find a ready outlet, and as the demand often exceeds the supply, a manufactured article is furnished to the rival crews."

During these investigations I have received samples of teas, both green and black, imported into this country from China, which are known, by the most experienced brokers, not to contain a single leaf of tea, and which were sold at public sale in bond at from $1 \frac{3}{4} d$. to $2 d$. per pound.

Again,- "The green tea for exportation undergoes some process which changes its colour, giving it a bluish green hue."

Mr. Davis $\ddagger$ gives the following important information on this subject:- 6 The tea farmers\$, who are small proprietors or cultivators, give the tea a rough preparation, and then take it to the contractors, whose business it is to adapt its further preparation to the existing nature of the demand."

* Article Thea in the 'Penny Cyclopædia.'

+ Article 'Thea, Medical and Dietetical, 'Penny Cyclopædia.'

† Davis's 'Chinese.' Vol, ii. p. 458. 
" Young hyson*, until spoiled by the large demand of the Americans, was a delicate, genuine leaf." "As it could not be fairly produced in any large quantities, the call for it on the part of the Americans was answered by cutting up and sifting other green teas through sieves of a certain size; and as the Company's inspectors detected the imposture, it formed no portion of their London importations. But the abuse became still worse of late, for the coarsest black tea leaves have been cut up, and then coloured with a preparation resembling the hue of green teas." At page $466 \mathrm{Mr}$. Davis continues, after speaking of the frauds with spurious and adulterated teas which the Chinese had endeavoured to practise, "But this was nothing in comparison with the effrontery which the Chinese displayed in carrying on an extensive manufactory of green teas from damaged black leaves, at a village or suburb called Honân."

"The remission of the tea duties in the United States occasioned, in the years 1832 and 1833, a demand for green teas at Canton which could not be supplied by the arrivals from the provinces. The Americans, however, were obliged to sail with cargoes of green teas within the favourable season; they were determined to have these teas, and the Chinese were determined they should be supplied. Certain rumours being afloat concerning the manufacture of green tea from old black leaves, the writer of this became curious to ascertain the truth, and with some difficulty persuaded a Hong merchant to conduct him, accompanied by one of the inspectors, to the place where the operation was carried on." " Entering one of these laboratories of fictitious hyson, the party were witnesses to a strange scene." The damaged black tea leaves, after being dried, were transferred to a cast iron pan placed over a furnace, and stirred rapidly with the hand, "a small quantity of turmeric in powder having been previously introduced; this gave the leaves a yellowish or orange tinge, but they were still to be made green. For this purpose some lumps of a fine blue were produced, together with a substance in powder, which, from the names given to them by the workmen, as well as their appearance, were known at once to be Prussian blue and gypsum. These were triturated finely together with a small pestle, in such proportions as reduced the dark colour of the blue to a light shade; and a quantity equal to a teaspoonful of the powder being added to the yellowish leaves, these were stirred as before over the fire, until the tea had taken the fine bloom colour of hyson, with very much the same scent. To prevent all possibility of error regarding the sub* p. 464.

Phil. Mag. S. 3. No. 162. Suppl. Vol. 24. 2 L 
stances employed samples of them were carried away from the place. The Chinese seemed quite conscious of the real character of the occupation in which they were engaged; for, on attempting to enter several other places where the same process was going on, the doors were speedily closed upon the party. Indeed, had it not been for the influence of the Hongist who conducted them, there would have been little chance of their seeing as much as they did*" "It is an interesting and important question to determine whether the same system of artificial colouring enters at all into the manufacture of the more genuine green teas brought to this country." "One fact is well ascertained and undeniable, that the Chinese themselves do not consume those kinds of green teas which are prepared for exportation t." " "The young hyson and Pekoe teas, made from the green tea plant, have a yellower and as it were a more natural hue than the bluish-green that distinguishes the elaborated teas imported to us."

Mr. Bruce states + that in the last operation for colouring the green teas "a mixture of sulphate of lime and iadigo, very finely pulverized and sifted through fine muslin, in the proportion of three of the former to one of the latter, is added to a pan of tea containing about seven pounds, about half a tea spoonful of this mixiure is put, and rubbed and rolled along with the tea in the pan for about an hour. The above mixture is merely to give it a uniform colour and appearance. The indigo gives it the colour, and the sulphate of lime fixes it. The Chinese call the former Youngtin, the latter Acco."

Indigo however, as previcusly stated, has never yet been met with on any of the green teas of commerce that have falden under my notice.

The following curious observation occurs in Maculloch's - Commercial Dictionary :-_s' Blue is a favourite colour with the Chinese; and in 181:0-11 the imports of Prussian blue into Canton from England amounted to 253,200 pounds. But for some years past the Chinese have not imported a single pound weight. The cause of the cessation of the trade deserves to be mentioned. A common Chinese sailor, who came to England in an East Indiaman, having frequented a manufactory where the dragg was prepared, learned the art of making it, and on his return to China he establistued a similar work there with such success that the whole empire is now supplied with native Prussian blue."

* Vol. ii. p. 468.

$\uparrow$ Vol. ii. p. 469.

₹ Report on the Manufacture of Tea, and on the extent and produce of the Tea Plantations in Assam, by Mr. C. A. Brace, Superintendent of Tea Culture, presented to the Tea Committee, August 16, 1839. 